Haberski, A., J. C. Hagelin, C. P. Barger, D. S. Sikes, and K. A. DuBour. 2021. An efficient method for sampling aerial arthropods at nest sites of an insectivorous songbird in steep decline. Avian Conservation and Ecology 16(2):1. https://doi.org/10.5751/ACE-01849-160201

Copyright (C) 2021 by the author(s). Published here under license by the Resilience Alliance.

Methodology

\title{
An efficient method for sampling aerial arthropods at nest sites of an insectivorous songbird in steep decline
}

\author{
Adam Haberski ${ }^{1}$ (D), Julie C. Hagelin ${ }^{2}$, Christopher P. Barger ${ }^{2}$, Derek S. Sikes ${ }^{1}$ and Kristin A. DuBour ${ }^{3,4}$ \\ ${ }^{1}$ University of Alaska Museum, University of Alaska Fairbanks, Fairbanks, AK, ${ }^{2}$ Threatened, Endangered and Diversity Program, \\ Alaska Department of Fish and Game, Fairbanks, AK, ${ }^{3}$ Tetlin National Wildlife Refuge, U.S. Fish and Wildlife Service, Tok, AK, \\ ${ }^{4}$ Current address: National Wildlife Refuge System, U.S. Fish and Wildlife Service, Anchorage, AK
}

\begin{abstract}
The decline of aerial insectivorous birds has been hypothesized to stem, in part, from a decline in aerial arthropod prey, underscoring the need for long-term monitoring of both bird and arthropod populations. However, trapping arthropods can be time consuming and efficient methods are required. Our primary goal was to identify the optimal combination of insect traps to collect taxonomic orders of prey in the diet of a songbird in steep decline, the Olive-sided Flycatcher (Contopus cooperi). Our secondary goal was to sample the arthropod community as broadly as possible, and thereby monitor for general changes in arthropod assemblages, which may affect multiple species of migratory insectivores. In the boreal forest of central Alaska, we compared captures of canopy Malaise traps and three types of near-ground pollinator traps (blue vane traps, yellow vane traps, and chemically baited wasp traps) at 22 breeding territories where adult flycatchers actively foraged and bred. Combined, traps collected 11,193 specimens from 12 arthropod orders, of which moths (Lepidoptera, 36\%), flies (Diptera, 34\%), and wasps (Hymenoptera, 18\%) were the most abundant, and also known components of flycatcher diets. General linear mixed models determined that canopy Malaise traps collected the greatest overall ordinal richness (11 orders) with a significantly greater abundance of specimens from six orders, two of which are aquatic specialists linked to breeding success of Tree Swallows (Tachycineta bicolor), another declining aerial insectivore. The three types of near-ground pollinator traps overlapped in taxa collected, but blue vane traps captured the most flies, bees, and yellowjackets, all of which were not well represented in Malaise samples. All trap types failed to collect dragonflies (Odonata), a known prey item of breeding Olive-sided Flycatchers. We therefore conclude that a combination of canopy Malaise traps and blue vane traps, plus handnetting of dragonflies, is an efficient combination for quantifying prey abundance on Olive-sided Flycatcher territories, while simultaneously monitoring the broadest possible number of arthropod orders near flycatcher nests within the boreal forest.
\end{abstract}

\section{Une méthode efficace d'échantillonnage des arthropodes aériens sur les sites de nidification d'un passereau insectivore en forte baisse}

RÉSUMÉ. On pense que la baisse des oiseaux insectivores aériens a peut-être découlé, en partie, d'une diminution des arthropodes aériens, soulignant le besoin d'avoir un suivi à long terme des populations d'oiseaux et d'arthropodes mis en place. Cependant, le piégeage des arthropodes peut prendre beaucoup de temps et des méthodes efficaces pour ce faire sont nécessaires. L'objectif principal de notre étude était de déterminer la combinaison optimale de pièges à insectes permettant de collecter les ordres taxonomiques de proies dans le régime alimentaire d'un passereau en forte baisse, le Moucherolle à côtés olive (Contopus cooperi). Notre objectif secondaire était d'échantillonner la communauté d'arthropodes aussi largement que possible, et ainsi de surveiller les changements généraux dans les assemblages d'arthropodes, qui peuvent affecter plusieurs espèces d'insectivores migrateurs. Dans la forêt boréale du centre de l'Alaska, nous avons comparé les captures de pièges Malaise posés dans la canopée et de trois types de pièges à pollinisateurs installés près du sol (piège à palette bleue, piège à palette jaune et piège à guêpe appâté chimiquement) sur 22 territoires de nidification où les moucherolles adultes s'alimentent et nichent activement. Ensemble, les divers pièges ont permis de collecter 11193 spécimens appartenant à 12 ordres d'arthropodes; les papillons de nuit (Lepidoptera, 36\%), les mouches (Diptera, 34 \%) et les guêpes (Hymenoptera, $18 \%$ ) étaient les arthropodes les plus abondants, et également des composantes connus du régime alimentaire des moucherolles. Des modèles linéaires généralisés à effets mixtes ont permis de déterminer que les pièges Malaise ont recueilli la plus grande richesse ordinale globale (11 ordres), capturant un nombre significativement plus grand de spécimens de six ordres, dont deux spécialistes aquatiques liés au succès de reproduction des Hirondelles bicolores (Tachycineta bicolor), un autre insectivore aérien en diminution. Les taxons collectés au moyen des trois types de pièges à pollinisateurs installés près du sol se chevauchaient, mais les pièges à palette bleue ont permis de capturer le plus de mouches, d'abeilles et de guêpes jaunes, tous peu récoltés avec les pièges Malaise. Aucun piège n'a permis de collecter des libellules (Odonata), une proie régulière des Moucherolles à côtés olive en nidification. Nous concluons donc qu'une combinaison de pièges Malaise et de pièges à palette bleue, ainsi que la capture de libellules au moyen de filets à main, est efficace pour quantifier l'abondance des proies sur les territoires de Moucherolles à côtés olive, tout en surveillant simultanément le plus d'ordres d'arthropodes possible près des nids de moucherolles dans la forêt boréale.

Key Words: Alaska; boreal forest; aerial insectivore; Olive-sided Flycatcher; insects

Address of Correspondent: Adam Haberski, Department Of Plant And Environmental Sciences, 277 Poole Agricultural Center, Clemson University, Clemson, SC 29634-0310, habersk@clemson.edu 


\section{INTRODUCTION}

There is increasing evidence that aerial insectivorous birds are declining in parallel with their arthropod prey, underscoring the need for more long-term studies of both bird and prey abundance (Nebel et al. 2010, Smith et al. 2015, Imlay et al. 2017, Spiller and Dettmers 2019, Tallamy and Shriver 2021). However, collecting arthropods for ornithological research can be laborious, usually requiring repeated sampling at multiple locations. It is therefore desirable that collection methods be as efficient as possible (see Cooper and Whitmore 1990 for an overview of collecting methods). Some insect traps, like Malaise traps and vane traps, are advantageous because they work continuously, without supervision, and have the potential to generate standardized samples. Combining traps of different designs and colors can reduce bias and sample a wider scope of prey (Campbell and Hanula 2007, Moreira et al. 2016). This is particularly important for birds that employ multiple foraging strategies or that forage in multiple microhabitats (Wolda 1990).

The Olive-sided Flycatcher (Contopus cooperi; hereafter OSFL) is an aerial insectivore that nests in coniferous forests of North America but has experienced a dramatic ( $>75 \%)$ decline between 1980 and 2020 (Birdlife International 2020). OSFL diet spans at least eight arthropod orders, including spiders (Araneae), beetles (Coleoptera), flies (Diptera), true bugs (Hemiptera), bees and wasps (Hymenoptera), moths (Lepidoptera), dragonflies (Odonata) and grasshoppers (Orthoptera) (Meehan and George 2003, Altman and Sallabanks 2012). Typically, OSFL feed by sallying from high perches to intercept flying insects in canopy flyways, but birds also occasionally forage near the ground (Altman and Sallabanks 2012). In the boreal forest of central Alaska, birds exhibit near-ground foraging behavior near flowering vegetation less than $0.5 \mathrm{~m}$ tall, where moths, bumblebees (Hymenoptera: Apidae: Bombus spp.), and yellowjackets occur (Hymenoptera: Vespidae: Dolichovespula spp. and Vespula spp.; Hagelin et al. 2015). To properly monitor prey availability of OSFL, collection methods must therefore account for both aerial and near-ground feeding strategies.

The work presented here represents part of a larger field effort to characterize breeding biology and decline of OSFL in boreal Alaska, as well as the associated aerial arthropod community (Hagelin et al. 2015), which is important to many migratory birds and a potentially important food-related driver of decline for aerial insectivores (e.g., Spiller and Dettmers 2019). We evaluated both canopy Malaise traps and near-ground pollinator traps to develop the best collecting method that would not only track key components of OSFL diet, but simultaneously enable us to assess abundance for the maximum number of aerial arthropod orders near OSFL nests in the boreal forest.

Canopy Malaise traps are a variant of the popular Townes-style "terrestrial-tent" Malaise trap, which are suspended within forest canopy flyways (Skvarla et al. 2021), making them ideal for sampling diets of avian insectivores like OSFL. Four perpendicular mesh panels passively intercept flying insects and guide them into a collecting bottle at the top or capture arthropods that drop after striking an obstacle via a funnel-like collector at the bottom (Fig 1a). By contrast, near-ground pollinator traps typically attract pollinators and other insects via lures, such as brightly colored "vanes," which resemble large flowers (Fig. 1b- c), or via chemical bait (Fig 1d). Vane traps have been used successfully in Alaska (Rykken et al. 2014, Pampell et al. 2015). Trap color influences arthropod abundance and diversity, prompting us to evaluate two vane colors, blue and yellow (Toler et al. 2005, Campbell and Hanula 2007, Moreira et al. 2016, Hall 2018, Hall and Reboud 2019), as well as a commercial chemical bait for yellowjackets, an important OSFL prey (Altman and Sallabanks 2012).

Fig. 1. Four trap types used for arthropod collection: a) Canopy Malaise trap, b) blue vane trap, c) yellow vane trap, d) wasp trap with chemical bait inside, and e) schematic of pollinator trap deployment (dots of different shades indicate location of each trap type, with like pairs opposite each other).
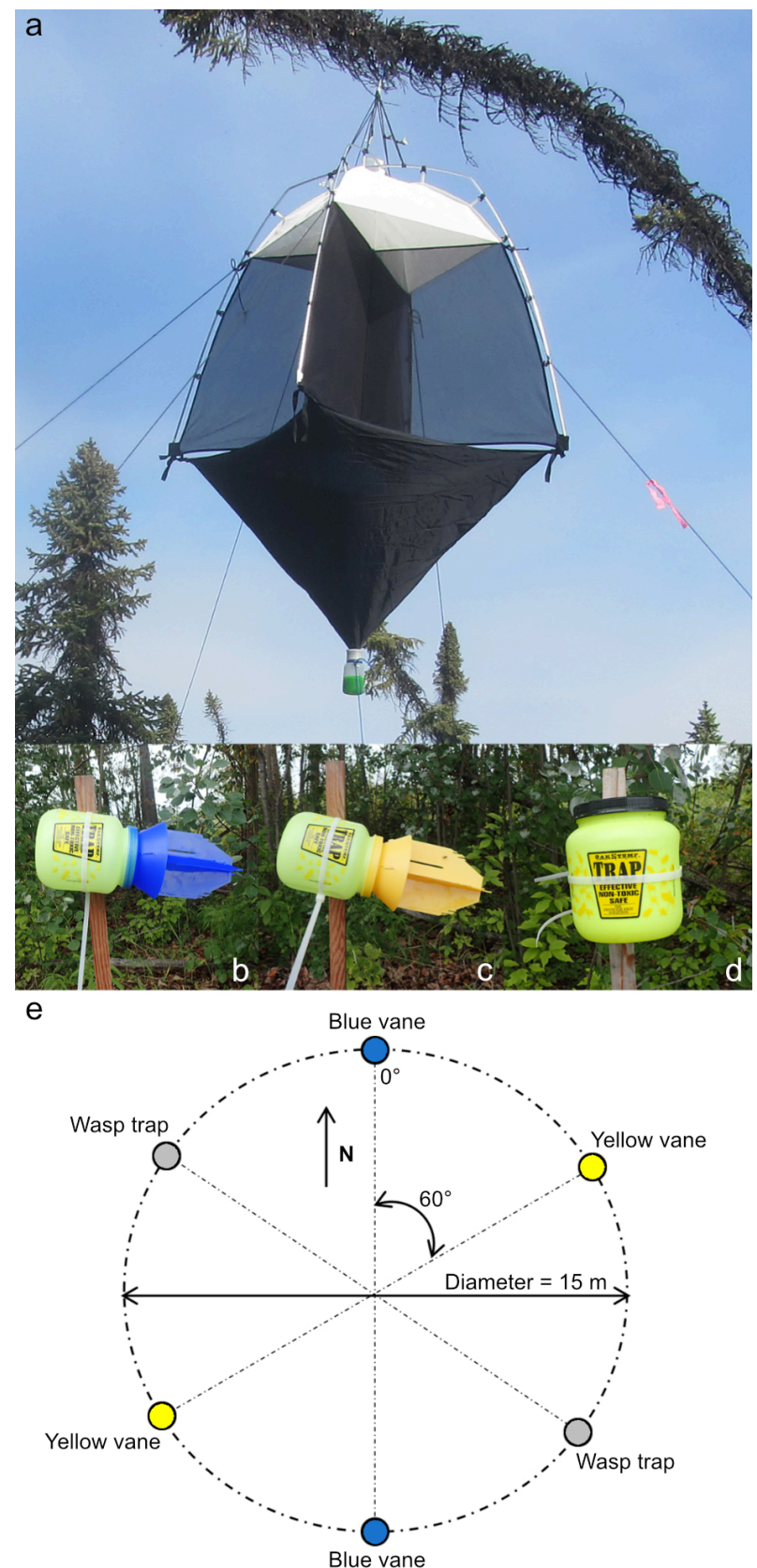
Our primary goal was to determine which combination of four trap types (canopy Malaise, three near-ground pollinator traps) collected the greatest abundance of individuals from a maximum number of taxonomic orders known to occur in OSFL diets. Ordinal analysis of arthropod prey has revealed important dietary and long-term patterns in other obligate aerial insectivores (e.g., Todd et al. 1998, Nocera et al. 2012, Orłowski and Karg 2013). Our study currently reflects the relatively coarse-level understanding of OSFL diet, while meeting the need to develop a protocol to standardize studies of potentially declining OSFL prey (e.g., Environment Canada 2015). Our secondary goal was to devise a method that also sampled the broadest portion of the aerial arthropod community within the boreal forest, by evaluating traps and trap pairings that maximized ordinal richness via complimentary sampling. For the same collection effort, broad (i.e., complimentary) sampling has the added benefit of potentially detecting general changes in arthropod assemblages, indicative of rapid ecological shifts, such as those occurring within Alaska, which may be applicable to a variety of migratory insectivores (e.g., Pérez et al. 2016, Asmus et al. 2018). To the best of our knowledge, this is the first study to quantitatively compare trapped contents of canopy Malaise traps with vane traps, both of which have a range of applied uses in studies of avian and arthropod ecology (Skvarla et al. 2020).

\section{METHODS}

\section{Study sites}

We collected arthropods at 22 OSFL nest sites located in the boreal forest of central Alaska, including 14 sites near Fairbanks, Alaska, and eight sites in Tetlin National Wildlife Refuge during 2016 (Fig. 2). The specific Alaska vegetation types sampled were "scattered woodland/dwarf forest and coniferous forest" described in Kessel (1979) as types VI.d. and VI.b., respectively, which is comparable to open needleleaf forest of Viereck et al (1992) types I.A.2, especially I.A.2.e, f. Nests were primarily located in black spruce (Picea mariana) trees, although two nests were in mixed stands of white spruce (Picea glauca) and aspen (Populus tremuloides). The dominant flowering plants present included Labrador tea (Ledum sp.), low bush cranberry (Vaccinium vitis-idaea), fireweed (Chamerion augustifolium), prickly rose (Rosa acicularis), and willow (Salix spp.).

\section{Arthropod collection}

Arthropod collection traps were deployed between 13 June - 29 July 2016. This duration encompasses the approximate nestling period of OSFL in central Alaska (Altman and Sallabanks 2012; Hagelin et al. 2020). Traps were deployed for two-week intervals and each trap site was sampled between one and three times (Table 1). In total, we collected $N=44$ samples of each trap type described below.

We deployed the four trap types in forest clearings. Each clearing was within $100 \mathrm{~m}$ of an active OSFL nest and represented a known feeding location of the resident breeding pair. We used BugDorm SLAM (Sea, Land, and Air Malaise) brand canopy Malaise traps (Mega View Science, Taiwan; https://www.shop.bugdorm.com) with the added bottom collector. Bottom collectors were included because they can increase a sample's richness of bark beetles (Curculionidae: Scolytinae), a known prey item of OSFL in California (Otvos and Stark 1985, DiGirolomo and Dodds 2017).
Fig. 2. Twenty-two Olive-sided Flycatcher nest sites in boreal forest of central Alaska, USA. Fourteen sites were within $\sim 90$ $\mathrm{km}$ of Fairbanks and eight sites were within the Tetlin National Wildlife Refuge. Table 1 provides sampling details for each site.

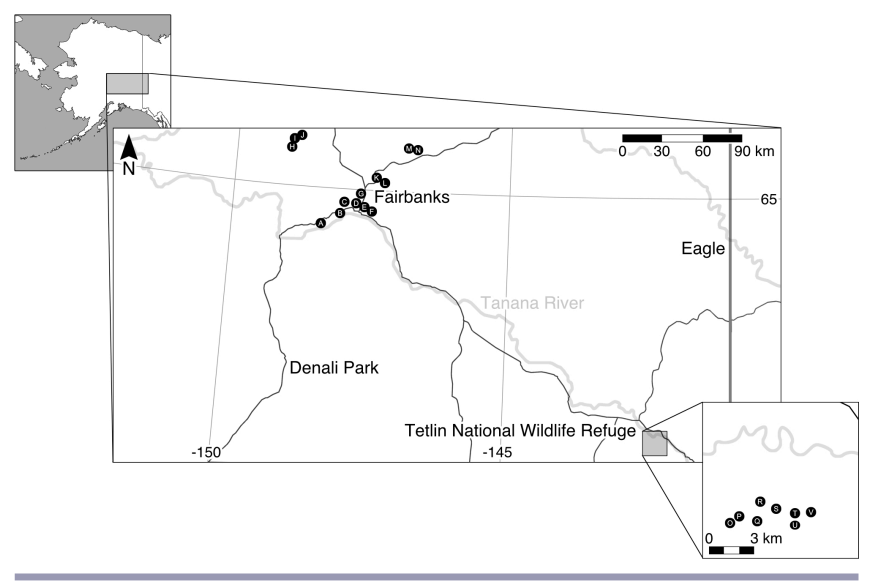

Table 1. Canopy Malaise trap height, number of samples, and approximate sampling period for 22 Olive-sided Flycatcher (Contopus cooperi) nest sites in central Alaska. All traps were deployed for 14 days at a time. Specific sampling dates varied by site but were within four days of the dates shown. Site codes refer to Figure 2.

\begin{tabular}{|c|c|c|c|c|c|}
\hline \multirow[t]{2}{*}{ Site } & \multirow{2}{*}{$\begin{array}{c}\text { Malaise } \\
\text { height }(\mathrm{m})\end{array}$} & \multirow[t]{2}{*}{$\mathrm{N}$} & \multicolumn{3}{|c|}{ Sampling periods } \\
\hline & & & $\begin{array}{l}13 \text { Jun - } \\
27 \text { Jun }\end{array}$ & $\begin{array}{l}27 \text { Jun - } \\
11 \text { July }\end{array}$ & $\begin{array}{c}11 \mathrm{Jul}- \\
25 \mathrm{Jul}\end{array}$ \\
\hline $\mathrm{A}$ & 6.2 & 2 & $\checkmark$ & $\bar{V}$ & \\
\hline B & 2.3 & 2 & $\checkmark$ & $\checkmark$ & \\
\hline $\mathrm{C}$ & 7.6 & 1 & & $\checkmark$ & \\
\hline $\mathrm{D}$ & 5.5 & 1 & $\checkmark$ & & \\
\hline $\mathrm{E}$ & 4.5 & 1 & $\checkmark$ & & \\
\hline $\mathrm{F}$ & 6.2 & 1 & $\checkmark$ & & \\
\hline $\mathrm{G}$ & 4.4 & 1 & $\checkmark$ & & \\
\hline $\mathrm{H}$ & 4.5 & 1 & & $\checkmark$ & \\
\hline I & 4.8 & 2 & $\checkmark$ & $\checkmark$ & \\
\hline $\mathbf{J}$ & 4.2 & 1 & & $\sqrt{ }$ & \\
\hline $\mathrm{K}$ & 5.7 & 2 & $\checkmark$ & $\checkmark$ & \\
\hline $\mathrm{L}$ & 2.4 & 2 & $\checkmark$ & $\checkmark$ & \\
\hline $\mathbf{M}$ & 7.9 & 1 & $\checkmark$ & & \\
\hline $\mathrm{N}$ & 4.7 & 2 & $\checkmark$ & $\checkmark$ & \\
\hline $\mathrm{O}$ & 5.5 & 3 & $\checkmark$ & $\checkmark$ & $\checkmark$ \\
\hline $\mathrm{P}$ & 6.0 & 3 & $\checkmark$ & $\checkmark$ & $\checkmark$ \\
\hline $\mathrm{Q}$ & 8.1 & 3 & $\checkmark$ & $\checkmark$ & $\checkmark$ \\
\hline $\mathrm{R}$ & 7.4 & 3 & $\checkmark$ & $\checkmark$ & $\checkmark$ \\
\hline $\mathrm{S}$ & 5.5 & 3 & $\checkmark$ & $\checkmark$ & $\checkmark$ \\
\hline $\mathrm{T}$ & 5.0 & 3 & $\checkmark$ & $\checkmark$ & $\checkmark$ \\
\hline $\mathrm{U}$ & 5.7 & 3 & $\checkmark$ & $\checkmark$ & $\checkmark$ \\
\hline $\mathrm{V}$ & 7.8 & 3 & $\checkmark$ & $\checkmark$ & $\checkmark$ \\
\hline
\end{tabular}

One Malaise trap was suspended from a tree branch at the margin of the clearing and secured against the wind with multiple guy lines (Fig. 1a). We positioned the trap at the same height as our field observations of foraging adult flycatchers, which was equivalent to, and limited by, the height of the surrounding trees in dwarfed boreal forest. Malaise trap height ranged from 2.3 - 
$8.1 \mathrm{~m}$ (Table 1). This range encompasses an ecologically realistic gradient of foraging space actively used by breeding OSFL in central Alaska. We recognize that trap height can alter arthropod captures (Campbell et al. 2018), so we also evaluated any relationship between trap height, abundance, and ordinal diversity of arthropod catch using Spearman's Rank Correlation (e.g., Gauthier 2001). We half-filled both of the trap's 500-ml collecting bottles with propylene glycol, which acted as both preservative and killing agent. To separate specimens from the glycol preservative, we strained the samples through fine mesh (mosquito netting). Glycol was replaced following arthropod collection.

To collect near-ground pollinators, we used three trap types: (1) blue vane traps, (2) yellow vane traps, and (3) yellowjacket traps (Springstar Inc., Woodinville, Washington). Yellowjacket traps are hereafter referred to as "wasp traps" to prevent name confusion with yellow vane traps. Six near-ground traps (two of each type) were deployed in a 15-m diameter circle (Fig. 1e). This diameter was recommended by the manufacturer to minimize interactions between traps of the same type (M. Banfield, Springstar Inc., personal communication). Positioning of trap pairs relative to north was alternated among sites in an effort to deploy the three possible trap configurations evenly across the landscape. Traps were mounted $25 \mathrm{~cm}$ above the ground on wooden stakes and positioned at a slight angle to the horizontal to prevent rainwater from entering (Fig. 1b-d). We placed a 2cm piece of Hercon ${ }^{\circledR}$ Vaportape ${ }^{\circledR}$ II (2,2 - dichlorovinyl dimethyl phosphate) pest strip in each trap as a killing agent. Wasp traps were baited with Springstar ${ }^{\mathrm{TM}}$ Yellowjacket and Wasp Lure, a sticky chemical attractant contained in an open 1.5-ml plastic microcentrifuge tube and suspended from the inside of the lid with a $5-\mathrm{cm}$ piece of wire. The wasp lure and pest strips were replaced every two weeks during arthropod collection.

All arthropod specimens were prepared and identified at the University of Alaska Museum. Specimens were prepared on pins or in vials of $70 \%$ ethanol and entered into the Arctosdb.org database, which shares data with GBIF.org and other data aggregators. Given time constraints and volume of material collected, all specimens were identified to taxonomic order. This approach has yielded informative patterns in dietary studies of other avian aerial insectivores (e.g., Todd et al. 1998, Nocera et al. 2012, Orłowski and Karg 2013). However, two groups within the order Hymenoptera, bumblebees (Apidae: Bombus spp.), and yellowjackets (Hymenoptera: Vespidae: Dolichovespula spp. and Vespula spp.) were also counted separately, because they were readily identifiable, abundant in samples, and well-known prey items of OSFL in Alaska. Data are available at https://doi. org/10.6084/m9.figshare.14128886.v1. Voucher specimens were deposited in the University of Alaska Museum Insect Collection and are available at http://arctos.database.museum/project/10002096.

\section{Data analysis}

We used general linear mixed models (GLMM) to quantify differences in mean abundance and ordinal richness among the four trap types. We assumed a negative binomial distribution for abundance data and a Poisson distribution for richness data. Samples taken at the same nest location are not independent, so we assigned "nest site" as a random variable in our models. We used parametric bootstrapping, as described by Harrison (2014), to test models for overdispersion but found no evidence thereof. For each arthropod order with more than 10 observations, we used six post-hoc t-tests to quantify any relative differences among trap types. Relative differences in abundance data reflect the relative effectiveness of each trap type at capturing individuals of a given order. We analyzed bumblebees and yellowjackets separately from ordinal analyses.

Complimentary traps sample a broader portion of the available arthropod community. To compare complementarity among trap types, we used Morisita's index of similarity. Morisita's index measures the amount of overlap between two samples on a scale of zero to one, with zero representing no overlap and one representing complete overlap of the arthropod community (Morisita 1959). Morisita's index was chosen because it is independent of both sample size and diversity (Morisita 1959, Wolda 1981). Complementarity between Malaise and pollinator traps, however, may also depend on Malaise trap height. For example, our lowest Malaise trap was positioned less than one meter above the pollinator traps and may have been more likely to sample the same near-ground community than higher-placed traps. We therefore checked for a relationship between Malaise trap height and amount of overlap with the near-ground pollinator traps using Spearman's Rank Correlation.

Specimens measuring less than $3 \mathrm{~mm}$ in head-to-abdomen length were considered too small for OSFL prey and were thus excluded from all analyses (Meehan and George 2003). Singletons, orders represented by only a single individual, were also excluded. All data analyses were performed in the statistical software package R V3.5.1 (R Core Team 2018), with the vegan (Oksanen et al. 2018), lme4 (Bates et al. 2015), multicomp (Hothorn et al. 2008), and ggplot2 (Wickham 2016) packages.

\section{RESULTS}

We collected 11,193 individual arthropods, representing 12 orders (Table 2). Lepidoptera (36\% of individuals), Diptera (34\%), and Hymenoptera (18\%) were the most abundant. No specimens of Odonata were collected. One individual each of Psocoptera and Orthoptera were collected but excluded from quantitative analyses (Table 2).

Trap types differed significantly in mean abundance $\left(\mathrm{df}=3, \chi^{2}=\right.$ $197.69, p<0.0001)$ and mean ordinal richness ( $\mathrm{df}=3, \chi^{2}=85.22$, $p<0.0001)$ of individuals collected. Canopy Malaise traps collected the most individuals overall $(55 \%)$ and the greatest mean abundance for six of the nine taxonomic orders (Fig. 3). Of the three near-ground pollinator trap types, blue vane traps collected over three times as many individuals over the entire study period as yellow vane traps or wasp traps (Table 2), and blue vanes also collected more individuals on average (Fig. 31). Blue vane traps were the best trap overall for collecting Hymenoptera, especially Bombus spp., and significantly exceeded other pollinator trap types in capturing Coleoptera and Diptera (Fig. 3). Neither yellow vane traps nor wasp traps collected any unique orders, nor did they collect the greatest abundance of any arthropod group.

Mean ordinal richness was greater in canopy Malaise traps (mean $=6$ orders per sample) than near-ground pollinator traps (mean $=3-4$ orders per sample; Fig. $3 \mathrm{~m}$ ). Among pollinator traps, blue vanes had higher mean ordinal richness than wasp traps but did not differ significantly from yellow vanes (Fig. $3 \mathrm{~m}$ ). Malaise trap 
Fig. 3. Mean $( \pm S E)$ abundance and ordinal richness collected from $N=44$ samples each of canopy Malaise traps and three pollinator traps (blue vane traps, yellow vane traps, and wasp traps). Capital letters indicate significantly different means at $\alpha=0.05$ as determined by general linear mixed models with post-hoc t-tests.
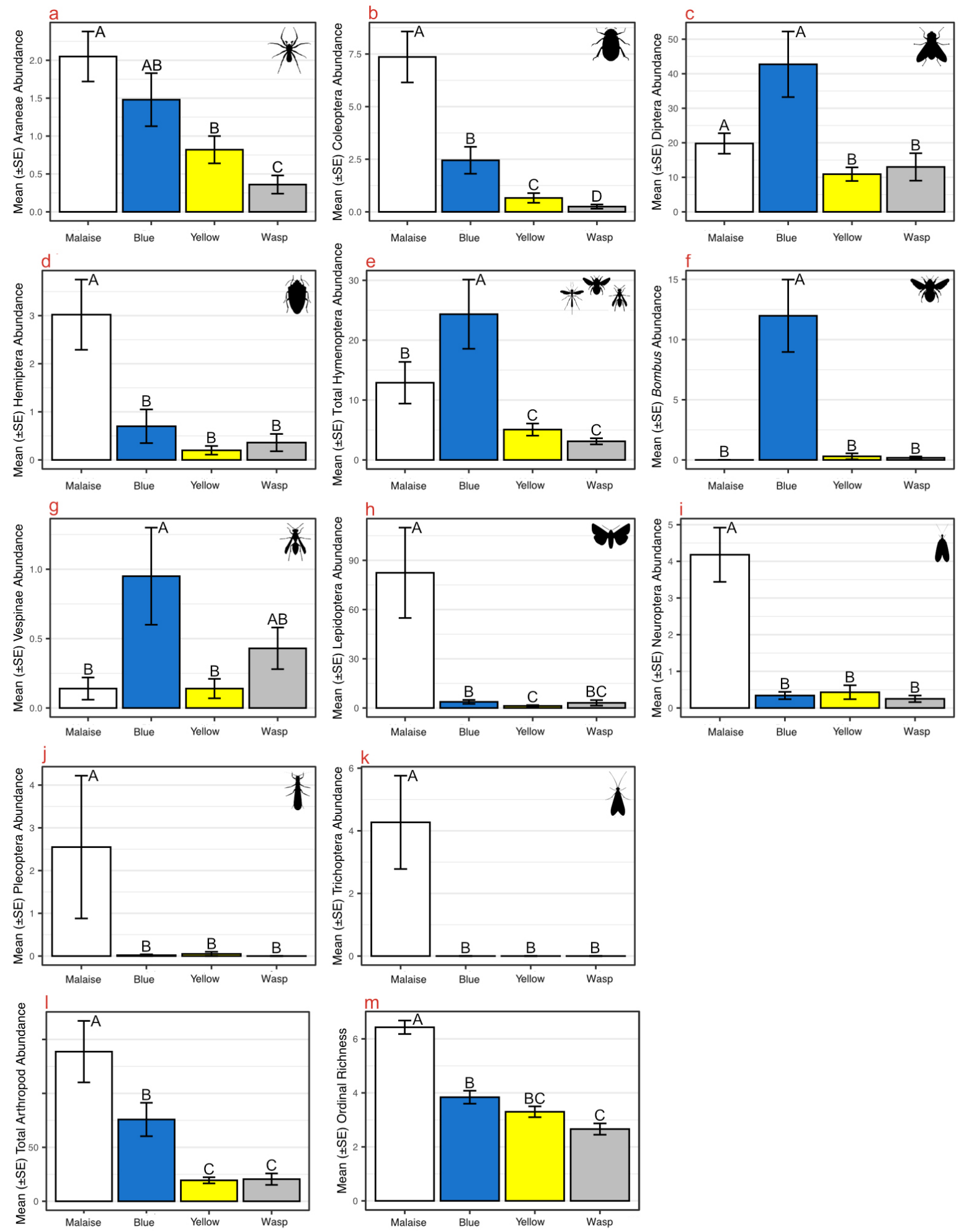
Table 2. Summary of arthropod abundance (by taxonomic order) collected by canopy Malaise traps and three types of near-ground pollinator traps (blue vane, yellow vane, and wasp traps) at Olive-sided Flycatcher (Contopus cooperi) nesting sites in central Alaska.

\begin{tabular}{lrcccc}
\hline \hline Taxon & Total & Malaise (\%) & Blue (\%) & Yellow (\%) & Wasp (\%) \\
\hline Araneae & 207 & $90(43)$ & $65(31)$ & $36(17)$ & $16(8)$ \\
Coleoptera & 472 & $324(69)$ & $108(23)$ & $29(6)$ & $11(2)$ \\
Diptera & 3803 & $871(23)$ & $1880(49)$ & $480(13)$ & $572(15)$ \\
Ephemeroptera & 8 & $8(100)$ & 0 & 0 & 0 \\
Hemiptera & 189 & $133(70)$ & $31(16)$ & $9(5)$ & $16(8)$ \\
Hymenoptera (all) & 1998 & $567(28)$ & $1071(54)$ & $223(11)$ & $137(7)$ \\
Bombus spp. & 548 & 0 & $527(96)$ & $13(2)$ & $8(1)$ \\
Vespinae & 73 & $6(8)$ & $42(58)$ & $6(8)$ & $19(26)$ \\
Lepidoptera & 3984 & $3626(91)$ & $164(4)$ & $56(1)$ & $138(3)$ \\
Neuroptera & 229 & $184(80)$ & $15(7)$ & 0 & $11(5)$ \\
Odonata & 0 & 0 & 0 & $1(100)$ & 0 \\
Orthoptera & 1 & 0 & 0 & $2(2)$ & 0 \\
Plecoptera & 115 & $112(97)$ & $1(100)$ & 0 & 0 \\
Psocoptera & 1 & $188(100)$ & 0 & 0 & 0 \\
Trichoptera & 188 & $6103(55)$ & $3335(30)$ & $854(8)$ & 0 \\
Total & 11,193 & & & $901(8)$ \\
\hline
\end{tabular}

height was not strongly correlated with either arthropod abundance $\left(r_{s}(42)=0.26, p=0.09\right)$ nor ordinal richness $\left(r_{s}(42)\right.$ $=0.09, p=0.56)$.

Canopy Malaise traps and pollinator traps are designed to sample different microhabitats. This was confirmed by Morisita's index which showed low overlap between them (Table 3). However, all three pollinator traps exhibited near complete overlap. Malaise trap height was not correlated with overlap between Malaise and pollinator trap contents $\left(r_{s}(20)=-0.27, p=0.22\right)$, indicating that low-hanging Malaise traps were not more likely to sample the same arthropods attracted to our near-ground pollinator traps.

Table 3. Trap complementarity using Morisita's index of similarity. Values range from 0 (no overlap) to 1 (complete overlap).

\begin{tabular}{lccc}
\hline \hline Trap Type & Malaise & Blue vane & Yellow vane \\
\hline Blue vane & 0.34 & - & - \\
Yellow vane & 0.38 & 0.98 & - \\
Wasp & 0.47 & 0.99 & 0.97 \\
\hline
\end{tabular}

\section{DISCUSSION}

\section{Canopy Malaise and blue vane traps provide the most efficient sampling method}

Our primary goal was to develop a standardized approach to sampling aerial insects available to breeding OSFL, a steeply declining aerial insectivore that exhibits both canopy and nearground foraging behaviors. We evaluated four trap types (canopy Malaise traps, blue vane traps, yellow vane traps, and chemically baited wasp traps) on OSFL breeding territories in the boreal forest of central Alaska. Our analysis suggests a combination of only two trap types, canopy Malaise traps and blue vane traps, are needed to collect most taxa of arthropod prey. The two-trap protocol alone efficiently collected large quantities of individuals for six of the eight arthropod prey orders reported for OSFL diets in North America: spiders (Araneae), beetles (Coleoptera), flies (Diptera), true bugs (Hemiptera), bees and wasps (Hymenoptera), and moths (Lepidoptera; Meehan and George 2003, Altman and Sallabanks 2012; Table 2, Fig. 3). An additional method to sample the remaining two arthropod orders (dragonflies and grasshoppers) is considered separately, below.

Our secondary goal was to ensure our trapping efforts also sampled the broadest-possible portion of the aerial arthropod community in the boreal forest. Pairing canopy Malaise with nearground blue vane traps yielded the greatest ordinal richness values and highest level of trap complementarity, as well as greatest abundance of individuals captured. In total, the method not only sampled the six common orders of OSFL prey, but also detected specimens from five other arthropod orders: mayflies (Ephemeroptera), net-winged insects (Neuroptera), stoneflies (Plecoptera), bark lice (Psocoptera), and caddisflies (Trichoptera; Table 2). Stoneflies and caddisflies are wetland specialists that provide critical omega-3 fatty acids and predicted breeding success in Tree Swallows (Tachycineta bicolor), another declining aerial insectivore, better than insect biomass alone (Twining et al. 2018). Our two-trap method is therefore capable of sampling other arthropod orders that may represent a key food resource for young OSFL and/or other avian breeders in wetland habitats. Finally, our protocol offers an added benefit of maximizing the available information about boreal arthropod orders per unit trapping effort. Broad changes in arthropod assemblages are not only central to the food web of many boreal insectivores but can also reveal important and rapid shifts in ecological patterns within Alaska (e.g., Pérez et al. 2016, Asmus et al. 2018).

We suggest eliminating half of our trap types (yellow vane traps and wasp traps), due to duplicative sampling of arthropod orders and/or low specimen numbers. A 50\% reduction in traps represents considerable savings in both cost and field effort for large or long-term monitoring studies. A focus on arthropod orders has successfully detected dietary differences and long-term patterns in other avian aerial insectivores (e.g., Todd et al. 1998, 
Nocara et al. 2012, Orłowski and Karg 2013). The approach is appropriate for OSFL, given our relatively coarse-level understanding of diet, but need for a standardized protocol to monitor potentially declining prey (e.g., Environment Canada 2015, Tallamy and Shriver 2021). We nonetheless caution that ordinal-level quantification has some limitations. First, this method implies that lower-level taxonomic groups (e.g., families) are sampled evenly within each order, even though some (like Coleoptera) are ecologically and morphologically diverse. Second, analyses are limited to detecting gross patterns, which may change with finer-scale taxonomic identification. For example, our approach may have been unable to detect differential attraction among families to yellow versus blue colored traps, as reported for certain fly and wasp families outside of the boreal forest (Hoback et al. 1999, Vrdoljak and Samways 2012, Hall and Reboud 2019). Future resolution of OSFL diet promises an opportunity to hone protocols to an appropriate taxonomic level and ensure that trapping targets key arthropod groups. For example, we did not separate fly families within the order Diptera, but we did separate bumblebees and yellowjackets within Hymenoptera, because field observations in boreal Alaska indicated OSFL commonly consume both groups (Altman and Sallabanks 2012, Hagelin personal observation).

\section{Additional techniques and modifications}

None of our traps collected appreciable numbers of dragonflies (Odonata) or grasshoppers (Orthoptera), even though both were observed at our study sites and are known components of OSFL diet (Altman and Sallabanks 2012). Dragonflies, in particular, are a common prey of breeding OSFL pairs in Alaska (Altman and Sallabanks 2012). As aquatic specialists, dragonflies may be a source of omega-3 fatty acids, critical to reproduction and chick performance, as quantified in Tree Swallows (Twining et al. 2016, 2018). These facts make an additional collection method necessary. Meehan and George (2003) modified their canopy Malaise traps by replacing the collecting jars with adhesive panels that succeeded in capturing a small number of grasshoppers but no dragonflies. The most common methods for surveying dragonflies are point counts and hand-netting (e.g., Hofmann and Mason 2005, Oppel 2006, Sherman 2019). The latter approach is also effective for collecting grasshoppers, enabling sampling of both taxa at once (Neill et al. 2002). Active net collecting does not offer the same advantages as trapping, which works continuously without supervision. Nonetheless, netting is simple, inexpensive, and replicable when methods are standardized (Neill et al. 2002). We therefore recommend handnetting in addition to the canopy Malaise and blue-vane trapping method in future OSFL studies. Repeated ground surveys can disturb boreal forest understory vegetation, which is sensitive to trampling, and thereby alter the composition of vegetation and ground-dwelling arthropod communities (Grandchamp et al. 2000, Lehvävirta et al. 2006, Hamberg et al. 2010, Kotz et al. 2012). However, net surveys could be designed to minimize impact, similar to bird nest search and monitoring protocols that require multiple visits (e.g., Martin and Geupel 1993, Martin et al 1997). This would reduce even moderate trampling that we observed at some OSFL trap arrays.

We further recommend modifying our trapping protocol by eliminating the canopy Malaise trap bottom collector. The bottom collector was initially included because it increases bark beetle richness (DiGirolomo and Dodds 2017). However, all bark beetles we collected were less than $3 \mathrm{~mm}$ long and thus unlikely OSFL prey (Meehan and George 2003). Qualitative observations indicated bottom collectors also yielded notably smaller catches (Haberski personal observation), though we did not formally quantify the difference between top versus bottom. Finally, bottom collectors were often problematic because they frequently filled with debris, snagged on branches, and flooded with rainwater, risking loss of collected specimens.

Wasp traps were included in our study because yellowjackets are important prey for OSFL (Altman and Sallabanks 2012). However, the near-ground chemical trap type we used did not collect significantly more yellowjackets than blue vane traps and performed poorly overall at our study sites (Fig. 3). A possible explanation is that wasp trap performance is lure dependent. Our commercial lure was made from a combination of mashed fruits and preservatives, but fruit volatiles can be less attractive to yellowjacket workers than other chemicals (Day and Jeanne 2001). Hepytl butyrate, isobutanol, and acetic acid have proven to be effective lures in Alaska and may improve the traps' productivity (Landolt et al. 2005). Timing of bait type may also be a factor, as yellowjackets may seek protein more readily in late summer (Spurr 1996).

In conclusion, we recommend a combination of canopy Malaise traps and near-ground blue vane traps, supplemented with handnetting dragonflies and grasshoppers, as an efficient, standardized solution for monitoring arthropod prey abundance and aerial arthropod communities at OSFL nest sites in boreal Alaska. This method targets the greatest number of individuals and broadest diversity of arthropod orders that also overlap with known OSFL prey. The boreal forest is the largest forest ecosystem in North America and the breeding ground of numerous migratory songbirds (Robbins et al. 1989), many of which are in decline and rely on arthropod prey (Nebel et al. 2010, Smith et al. 2015, Spiller and Dettmers 2019). Our results are therefore widely applicable to ongoing studies of diet as a possible mechanism of decline for avian insectivores of conservation concern (Tallamy and Shriver 2021), as well as a method to quantify broader, long-term, or rapid patterns of change in arthropod assemblages within boreal forest ecosystems.

Responses to this article can be read online at: https://www.ace-eco.org/issues/responses.php/1849

\section{Acknowledgments:}

We thank Nicole Kelly, Janelle Badger, and Haley Heniff, as well as Fairbanks ADF\&G and Tetlin NWR field technicians Eva Allaby, Keegan Crowley, Sara Germain, Constance Johnson, Elise Stacey, and J. Byron de Yampert for their assistance in deploying traps and collecting specimens. We also thank Mary Wyatt, Jayce Williamson, Renee Nowicki, Miles McHugh, Zack Snelson, and the University of Alaska Museum for preparing and databasing specimens. Comments of two anonymous reviewers greatly improved an earlier version of this manuscript. Funding was provided through a State Wildlife Grant ( $S W G$ ) administered by the Alaska 
Department of Fish and Game's Threatened, Endangered and Diversity Program. Tetlin National Wildlife Refuge provided funding, logistical and technical support for sampling at eight refuge sites. The findings and conclusions in this article are those of the author(s) and do not necessarily represent the views of the U.S. Fish and Wildlife Service.

\section{LITERATURE CITED}

Altman, B., and R. Sallabanks, 2012. Olive-sided Flycatcher (Contopus cooperi), version 2.0. In: The Birds of North America. Cornell Lab of Ornithology, Ithaca, NY. https://doi.org/10.2173/ bna. 502

Asmus, A. L., H. E. Chmura, T. T. Høye, J. S. Krause, S. K. Sweet, J. H. Perez, N. T. Boelman, J. C. Wingfield, and L. Gough. 2018. Shrub shading moderates the effects of weather on arthropod activity in arctic tundra. Ecological Entomology 43:647-655. https://doi.org/10.1111/een.12644

Bates, D., M. Maechler, B. Bolker, B. and O. Walker. 2015. Fitting linear mixed-effects models using lme4 R. Journal of Statistical Software 67:1-48. https://doi.org/10.18637/jss.v067.i01

Birdlife International. 2020. Olive-sided Flycatcher: Contopus cooperi. Species factsheet. [online] URL: http://www.birdlife.org. (Accessed 15 December: 2020).

Campbell, J. W., and J. L. Hanula. 2007. Efficiency of Malaise traps and colored pan traps for collecting flower visiting insects from three forested ecosystems. Journal of Insect Conservation 11: 399-408. https://doi.org/10.1007/s10841-006-9055-4

Campbell, J. W., P. A. Vigueira, C. C. Vigueira, and C. H. Greenberg. 2018. The effects of repeated prescribed fire and thinning on bees, wasps, and other flower visitors in the understory and midstory of a temperate forest in North Carolina. Forest Science 64:299-306. https://doi.org/10.1093/forsci/fxx008

Cooper, R. J., and R. C. Whitmore. 1990. Arthropod sampling methods in ornithology. Studies in Avian Biology 13:29-37.

Day, S. E., and R. L. Jeanne. 2001. Food volatiles as attractants for yellowjackets (Hymenoptera: Vespidae). Environmental Entomology 30:157-165. https://doi.org/10.1603/0046-225X-30.2.157

DiGirolomo, M. F., and K. J. Dodds. 2017. Comparison of the species richness and abundance of Cerambycidae (Coleoptera) and Scolytinae (Coleoptera: Curculionidae) captured in aerial Malaise traps with and without a bottom collector. The Canadian Entomologist 149:1-5. https://doi.org/10.4039/tce.2016.70

Environment Canada. 2015. Recovery strategy for Olive-sided Flycatcher (Contopus cooperi) in Canada [Proposed]. Species at Risk Act Recovery Strategy Series. Environment Canada, Ottawa. $\mathrm{vi}+51$ pp. https://www.registrelep-sararegistry.gc.ca/default.asp? lang=En\&n=10AA870D-1

Gauthier, T. D. 2001. Detecting trends using Spearman's Rank Correlation Coefficient. Environmental Forensics 2:359-362. https://doi.org/10.1006/enfo.2001.0061

Grandchamp, A.C., J. Niemelä, and J. Kotze. 2000. The effects of trampling on assemblages of ground beetles (Coleoptera, Carabidae) in urban forests in Helsinki, Finland. Urban Ecosystems 4:321-332. https://doi.org/10.1023/A:1015707916116
Hagelin, J. C., S. Busby, A. Harding-Scurr, and A. R. Brinkman. 2015. Observations on fecal sac consumption and near-ground foraging behavior in the Olive-sided Flycatcher (Contopus cooperi). The Wilson Journal of Ornithology 127:332-336. https://doi.org/10.1676/wils-127-02-332-336.1

Hagelin, J.C., J. A. Johnson, and K. A. DuBour. 2020. Olive-sided Flycatcher migration and breeding biology. 2019 Boreal Partners in Flight Summary of Landbird Projects 21-24. https://www.usgs. gov/centers/asc/science/meeting-and-project-summaries-boreal-partnersflight

Hall, M. 2018. Blue and yellow vane traps differ in their sampling effectiveness for wild bees in both open and wooded habitats: blue vane traps better for bee sampling. Agricultural and Forest Entomology 20:487-495. https://doi.org/10.1111/afe.12281

Hall, M. A., and E. L. Reboud. 2019. High sampling effectiveness for non-bee flower visitors using vane traps in both open and wooded habitats. Austral Entomology 54:836-847. https://doi. org/10.1111/aen.12416

Hamberg, L., M. Malmivaara-Lämsä, S. Lehvävirta, R. B. O'Hara, and D. J. Kotze. 2010. Quantifying the effects of trampling and habitat edges on forest understory vegetation-a field experiment. Journal of environmental management 91:1811-1820. https://doi.org/10.1016/j.jenvman.2010.04.003

Harrison, X. A. 2014. Using observation-level random effects to model overdispersion in count data in ecology and evolution. PeerJ 2:e616. https://doi.org/10.7717/peerj.616

Hoback, W. W., T. M. Svatos, S. M. Spomer, and L. G. Higley. 1999. Trap color and placement affects estimates of insect familylevel abundance and diversity in a Nebraska salt marsh. Entomologia Experimentalis et Applicata 91:393-402. https://doi. org/10.1046/j.1570-7458.1999.00507.x

Hofmann, T. A., and C. F. Mason. 2005. Habitat characteristics and the distribution of Odonata in a lowland river catchment in eastern England. Hydrobiologia 539:137-147. https://doi. org/10.1007/s10750-004-3916-1

Hothorn, T., F. Bretz, and P. Westfall. 2008. Simultaneous inference in general parametric models. Biometrical Journal 50:346-363. https://doi.org/10.1002/bimj.200810425

Imlay, T. L., H. A. R. Mann, and M. L. Leonard. 2017. No effect of insect abundance on nestling survival or mass for three aerial insectivores. Avian Conservation and Ecology 12(2):19. https:// doi.org/10.5751/ACE-01092-120219

Kessel, B. 1979. Avian habitat classification for Alaska. The Murrelet 60:86-94. https://doi.org/10.2307/3534270

Kotze, D.J., S. Lehvävirta, M. Koivula, R. B. O'Hara, and J. R. Spence. 2012. Effects of habitat edges and trampling on the distribution of ground beetles (Coleoptera, Carabidae) in urban forests. Journal of Insect Conservation 16:883-897. https://doi. org/10.1007/s10841-012-9475-2

Landolt, P., A. Pantoja, and D. Green. 2005. Yellowjacket wasps (Hymenoptera: Vespidae) trapped in Alaska with heptyl butyrate, acetic acid and isobutanol. Journal of the Entomological Society of British Columbia 102:35-42. 
Lehvävirta, S., D. J. Kotze, J. Niemelä, M. Mäntysaari, and R. B. O'Hara. 2006. Effects of fragmentation and trampling on carabid beetle assemblages in urban woodlands in Helsinki, Finland. Urban ecosystems 9:13-26. https://doi.org/10.1007/s11252-006-5526-3

Martin, T. E. and G. R. Geupel. 1993. Nest-monitoring plots: Methods for locating nests and monitoring success. Journal of Field Ornithology 64:507-519.

Martin, T. E., C. R. Paine, C. J. Conway, W. M. Hochachka, P. Allen, and W. Jenkins. 1997. BBIRD Field Protocol. Montana Cooperative Wildlife Research Unit, University of Montana, Missoula, Montana, USA.

Meehan, T. D., and T. L. George. 2003. Short-term effects of moderate- to high-severity wildfire on a disturbance-dependent flycatcher in northwest California. The Auk 120:1102-1113. https://doi.org/10.1642/0004-8038(2003)120[1102:SEOMTH]2.0. $\mathrm{CO} ; 2$

Moreira, E. F., R. L. da Silva Santos, U. L. Penna, C. Angel-Coca, F. F. de Oliveira, and B. F. Viana. 2016. Are pan traps colors complementary to sample community of potential pollinator insects? Journal of Insect Conservation 20:583-596. https://doi. org/10.1007/s10841-016-9890-X

Morisita, M. 1959. Measuring of interspecific association and similarity between communities. Memoir of the Faculty of Science, Kyushu University, Series E (Biology) 3:65-80.

Nebel, S., J. D. McCracken, and P. D. Taylor. 2010. Declines of aerial insectivores in North America follow a geographic gradient. Avian Conservation and Ecology 5(2):1. https://doi.org/10.5751/ ACE-00391-050201

Neill, K. M. O., D. P. Larson, and W. P. Kemp. 2002. Sweep sampling technique affects estimates of the relative abundance and community composition of grasshoppers (Orthoptera: Acrididae). Journal of Agricultural and Urban Entomology 19:125-131.

Nocera, J. J., J. M. Blais, D. V. Beresford, L. K. Finity, C. Grooms, L E. Kimpe, K. Kyster, N. Michelutti, M. W. Reudink, and J. P. Smol. 2012. Historical pesticide applications coincided with an altered diet of aerially foraging insectivorous chimney swifts. Proceedings of the Royal Society Series B 27:3114-3120. https:// doi.org/10.1098/rspb.2012.0445

Oksanen, J. F., G. Blanchet, M. Friendly, R. Kindt, P. Legendre, D. McGlinn, P. R. Minchin, PR. B. O'Hara, G. L. Simpson, P. Solymos, M. H. H. Stevens, E. Szoecs, and H. Wagner. 2018. vegan: Community Ecology Package. R package version 2.4-6. https://CRAN.R-project.org/package=vegan

Oppel, S. 2006. Using distance sampling to quantify Odonata density in tropical rainforests. International Journal of Odonatology 9:81-88. https://doi.org/10.1080/13887890.2006.9748265

Orłowski G. and J. Karg. 2013. Diet breadth and overlap of three sympatric aerial insectivorous birds at the same location. Bird Study 60:475-483. https://doi.org/10.1080/00063657.2013.839622

Otvos, I. S., and R. W. Stark. 1985. Arthropod food of some forestinhabiting birds. The Canadian Entomologist 117:971-990. https://doi.org/10.4039/Ent117971-8
Pampell, R., D. S. Sikes, A. Pantoja, P. S. Holloway, C. Knight, and R. Ranft. 2015. Bumble bees (Hymenoptera: Apidae: Bombus spp.) of interior Alaska: species composition, distribution, seasonal biology, and parasites. Biodiversity Data Journal 3:e5085. https://doi.org/10.3897/bdj.3.e5085

Pérez, J. H., J. S. Krause, H. E. Chmura, S. Bowman, M. McGuigan, A. L. Asmus, S. L. Meddle, K. E. Hunt, L. Gough, N. T. Boelman, and J. C. Wingfield. 2016. Nestling growth rates in relation to food abundance and weather in the Arctic. The Auk 133:261-272. https://doi.org/10.1642/AUK-15-111.1

R Core Team. 2018. R: a language and environment for statistical computing. https://www.r-project.org/

Robbins, C. S., J. R. Sauer, R. S. Greenberg, and S. Droege. 1989. Population declines in North American birds that migrate to the neotropics. PNAS 86:7658-7662. https://doi.org/10.1073/pnas.86.19.7658

Rykken, J. J. 2014. Insect pollinators of Denali: a survey of bees and flower flies. Park Science 31:91-93. https://www.nps.gov/ subjects/parkscience/parkscience31-1-specialissue2014.htm

Sherman, L. M. 2019. Habitat associations and diet composition of Western Purple Martins in western Oregon. Oregon State University. https://ir.library.oregonstate.edu/concern/ graduate_thesis_or_dissertations/nk322k717

Smith, A. C., M.-A. R. Hudson, C. M. Downes, and C. M. Francis. 2015. Change points in the population trends of aerialinsectivorous birds in North America: synchronized in time across species and regions. PLoS One 10:e0130768. https://doi. org/10.1371/journal.pone.0130768

Spiller, K. J., and R. Dettmers. 2019. Evidence for multiple drivers of aerial insectivore declines in North America. The Condor 121:1-13. https://doi.org/10.1093/condor/duz010

Spurr, E. B. 1996. Carbohydrate bait preferences of wasps (Vespula vulgaris and V. germanica) (Hymenoptera: Vespidae) in New Zealand. New Zealand Journal of Zoology 23:315-324. https://doi.org/10.1080/03014223.1996.9518090

Skvarla, M. J., J. L. Larson, J. Fisher, and A. P. Dowling. 2021. A review of terrestrial and canopy Malaise traps. Annals of the Entomological Society of America 114:27-47. https://doi. org/10.1093/aesa/saaa044

Tallamy, D. W., and W. G. Shriver. 2021. Are declines in insects and insectivorous birds related? Ornithological Applications 123:1-8. https://doi.org/10.1093/ornithapp/duaa059

Todd L. D., R. G. Poulin, and R. M. Brigham. 1998. Diet of Common Nighthawks (Chordeiles minor: Caprimulgidae) relative to prey abundance. American Midland Naturalist 139:20-28. https://doi.org/10.1674/0003-0031(1998)139[0020:DOCNCM] 2.0. $\mathrm{CO} ; 2$

Toler, T. R., E. W. Evans, and V. J. Tepedino. 2005. Pan-trapping for bees (Hymenoptera: Apiformes) in Utah's West Desert: the importance of color diversity. The Pan-Pacific Entomologist 81:103-113.

Twining, C. W., J. T. Brenna, P. Lawrence, J. R. Shipley, T. N. Tollefson, and D. W. Winkler. 2016. Omega-3 long-chain polyunsaturated fatty acids support aerial insectivore 
performance more than food quantity. Proceedings of the National Academy of Sciences 113:10920-10925. https://doi. org/10.1073/pnas.1603998113

Twining, C. W., J. R. Shipley, and D. W. Winkler. 2018. Aquatic insects rich in omega-3 fatty acids drive breeding success in a widespread bird. Ecology Letters 21:1812-1820. https://doi. org/10.1111/ele.13156

Viereck, L. A., C. T. Dyrness, A. R. Batten, and K. J. Wenzlick. 1992. The Alaskan vegetation classification. General Technical Report PNW-GTR-286. US Department of Agriculture, Forest Service, Pacific Northwest Research Station 278-286. https://doi. org/10.2737/pnw-gtr-286

Vrdoljak, S. M. and M. J. Samways. 2012. Optimising coloured pan traps to survey flower visiting insects. Journal of Insect Conservation 16:345-354. https://doi.org/10.1007/s10841-011-9420-9

Wickham, H. 2016. ggplot2: elegant graphics for data analysis. Springer-Verlag, New York. https://doi.org/10.1007/978-3-319-24277-4_9

Wolda, H. 1981. Similarity indices, sample size and diversity. Oecologia 50:296-302. https://doi.org/10.1007/BF00344966

Wolda, H. 1990. Food availability for an insectivore and how to measure it. Studies in Avian Biology 13:38-43.

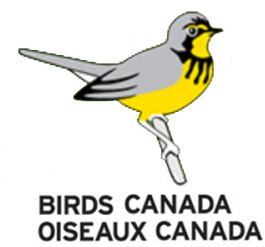

